\title{
APLIKASI KEPEGAWAIAN DINAS PENANGGULANGAN KEBAKARAN DAN PENYELAMATAN PADA SEKTOR 8 JAKARTA
}

\author{
Eko Yunianto Wibowo ${ }^{1}$, Fitriana Destiawati ${ }^{2}$, Dian Novita ${ }^{3}$ \\ Program Studi Teknik Informatika, Fakultas Teknik dan Ilmu Komputer, \\ Universitas Indraprasta PGRI \\ Jalan Raya Tengah No 80, Kelurahan Gedong, Pasar Rebo, Jakarta Timur \\ ekoy65fire@gmail.com ${ }^{1}$, honeyzone86@gmail.com ${ }^{2}$, dian.novita21@gmail.com ${ }^{3}$
}

\begin{abstract}
Abstrak
Saat ini pengolahan data kepegawaian pada Kantor Sektor 8 Dinas Penanggulangan Kebakaran dan Penyelamatan Jakarta Selatan masih secara manual. Penyimpanan data masih dalam bentuk arsip yang tersimpan dalam sebuah map kertas, sehingga membutuhkan ketelitian dan memakan waktu yang cukup lama pada saat pencarian data-data kepegawaian yang diinginkan. Berdasarkan masalah yang ditemukan, maka rumusan masalah pada penelitian ini adalah bagaimana merancang sebuah aplikasi kepegawaian yang lebih efektif dan efisien dalan penggunaannya. Dengan tujuan agar proses pendataan kepegawaian lebih cepat dan akurat. Metode yang digunakan dalam penelitian ini adalah Research \& Development. Dimana perancangan dimulai dari mengumpulkan kebutuhan dengan cara observasi dan wawancara. Kemudian dianalisis dan didefinisikan kebutuhan yang harus dipenuhi oleh program aplikasi yang akan dibangun. Langkah selanjutnya adalah melakukan desain aplikasi sistem yang diterjemahkan ke dalam kode-kode dengan menggunakan bahasa pemrograman Java.
\end{abstract}

Kata Kunci: java, kepegawaian, aplikasi, Research and Development

\begin{abstract}
Currently the processing of staffing data at the Sector 8 Office of the South Jakarta Fire and Rescue Service is still manually. Data storage is still in the form of archives stored in a paper folder, so it requires accuracy and takes a long time at the time of searching for the desired staffing data. Based on the problems found, the formula of the problem in this study is how to design a staffing application that is more effective and efficient in its use. With the aim that the staffing data collection process is faster and more accurate. The method used in this research is Research \& Development. Where design starts from collecting needs by means of observation and interview. It is then analyzed and defined the needs that must be met by the application program to be built. The next step is to design system applications that are translated into codes using the Java programming language.
\end{abstract}

Keywords: application, employee affair, java, Research and Development

\section{PENDAHULUAN}

Aplikasi adalah suatu bagian dari sebuah perangkat lunak komputer yang memanfaatkan kemampuan komputer langsung untuk melakukan suatu tugas yang diinginkan pengguna dalam memecahkan suatu masalah, (Abdurahman \& Riswaya, 2014).

Sistem adalah beberapa objek, unsur atau komponen yang saling terkait dan terhubung, sehingga menjadi satu kesatuan dalam pengolahan tertentu. (Prasojo, 2011). Sistem informasi merupakan satuan kerja yang saling berinteraksi untuk mendapatkan suatu informasi yang sesuai dengan sasarannya, (Priyanti, 2013).

Pegawai adalah subjek yang bekerja pada pemberi kerja berdasarkan kesepakatan kerja, untuk melaksanakan suatu pekerjaan dalam jabatan atau kegiatan tertentu, (Mardiasmo, 2011). Sedangkan sistem informasi kepegawaian adalah suatu sistem yang dirancang untuk mengelola data-data para pegawai, (Fachlevi \& Syafariani, 2017). 
Pengolahan data kepegawaian pada Kantor Sektor 8 Dinas Penanggulangan Kebakaran dan Penyelamatan Jakarta Selatan masih menggunakan sistem yang manual. Penyimpanan data kepegawaian masih dalam bentuk arsip yang tersimpan dalam sebuah map kertas, sehingga membutuhkan ketelitian dan memakan waktu yang cukup lama pada saat pencarian data-data kepegawaian yang diinginkan, maupun pada saat pembuatan laporan, serta dapat menyebabkan hilangnya arsip atau rusaknya arsip yang tersimpan.

Diharapkan dengan adanya suatu sistem informasi dalam bentuk suatu aplikasi kepegawaian dapat menangani permasalahan yang ada. Dengan dirancang dan dibuatnya sistem aplikasi informasi kepegawaian ini, nantinya dapat menghasilkan efisiensi dalam pengolahan data administrasi pegawai yang ditunjukan oleh kecepatan dan ketepatan waktu pemrosesan, serta ketelitian dan kebenaran informasi yang dihasilkan, sehingga dapat meningkatkan produktifitas kerja.

\section{PENELITIAN RELEVAN}

Dalam Penelitian yang berjudul Perancangan Sistem Informasi Kepegawaian Berbasis Website di Bagian Kepegawaian SDN Binakarya 1 Kabupaten Garut dengan peneliti Mohamad Reza Fachlevi, RF Syafariani memiliki permasalahan lambatnya proses pendataan data kepegawaian di SDN Binakarya 1 Kabupaten Garut karena pendataan nya masih manual. Sistem informasi kepegawaian digunakan pendekatan berorientasi objek (OOP) dan untuk metode pengembangan menggunakan metode prototipe, serta alat bantu yang digunakan adalah usecase, activity diagram, class diagram, object diagram dan deployment diagram. Simpulan dari penelitian ini adalah sebuah sistem informasi kepegawaian yang dapat membantu pegawai dalam menyiapkan persyaratan kenaikan pangkat kepensiunan penilaian pegawai dengan adanya sebuah database yang terintegrasi.(Fachlevi \& Syafariani, 2017)

Dalam penelitian yang berjudul Sistem Informasi Kepegawaian pada Rumah Sakit Umum Sari Mutiara Medan dengan peneliti Erwin Panggabean memiliki permasalahan masih sulitnya dalam proses pencarian data pegawai karena masih manual. Dengan pembuatan aplikasi system kepegawaian ini menggunakan Microsoft Visual Basic 6. Simpulan dari penelitian ini bahwa dengan menggunakan jasa komputer yang menggunakan sistem maka pelaporan data akan dapat dilakukan dengan cepat dan tidak memerlukan waktu yang lama maupun ruang penyimpanan yang besar dan komputerisasi dapat meningkatkan efektifitas kerja petugas di Rumah Sakit Umum Sari Mutiara Medan.

\section{METODE PENELITIAN}

Metode penelitian yang digunakan yaitu metode Research \& Development, dimana pengembangan didefinisikan sebagai aplikasi sistematis dari pengetahuan dan pemahaman, diarahkan pada produksi bahan yang bermanfaat, perangkat, dan sistem atau metode, termasuk desain, pengembangan dan peningkatan prioritas serta proses baru untuk memenuhi persyaratan tertentu.(Putra, 2011)

Kegiatan research dilakukan dengan mengumpulkan berbagai informasi tentang kebutuhan pengguna. Sedangkan kegiatan development merupakan suatu kegiatan yang dilakukan untuk menghasilkan suatu perangkat atau aplikasi.(Prasetyo, 2014)

Pada metode pengembangan system ini langkah pertama yang harus dilakukan adalah mengumpulkan kebutuhan secara lengkap dengan cara observasi dan wawancara pada pihak Kantor Sektor 8 Dinas Penanggulangan Kebakaran dan Penyelamatan Jakarta Selatan, kemudian dianalisis dan didefinisikan kebutuhan yang harus dipenuhi oleh program aplikasi yang akan dibangun. Fase ini harus dikerjakan secara lengkap untuk menghasilkan desain yang lengkap. Setelah melakukan analisa kebutuhan, langkah selanjutnya adalah melakukan desain aplikasi system. Kemudian desain program diterjemahkan ke dalam kode-kode dengan menggunakan bahasa pemrograman Java. Program aplikasi yang dibangun langsung dapat diuji keseluruhannya secara unit. Tahap terakhir adalah mengoperasikan program aplikasi dan melakukan pemeliharaan, seperti penyesuaian atau perubahan karena adaptasi dengan situasi sebenarnya.(Rumetna et al., 2020) 


\section{HASIL DAN PEMBAHASAN}

Analisa permasalahan pada sistem aplikasi kepegawaian dinas penanggulangan kebakaran dan penyelamatan pada Sektor 8 Jakarta Selatan ini ternyata mempunyai beberapa kelemahan karena sistem yang digunakan belum sepenuhnya terkomputerisasi.

1. Dalam proses input data pegawai, absensi, penilaian kinerja pegawai dan cuti pegawai masih ada yang dilakukan secara manual.

2. Pencarian data pegawai, data absensi, penilaian kinerja pegawai dan cuti pegawai membutuhkan waktu yang lama dan tidak efektif karena sistem yang ada masih manual sehingga jika mencari data yang dibutuhkan, pencarian dilakukan di arsip.

3. Sistem informasi yang belum terkomputerisasi menyebabkan admin menjadi terhambat dan kurang efisien.

4. Kurangnya sumber daya manusia yang memahami sistem komputerisasi.

5. Pembuatan laporan data pegawai, data absensi, penilaian kinerja pegawai dan cuti pegawai yang dilakukan secara manual memungkinkan terjadinya kesalahan data dan membutuhkan waktu yang lama dalam memperbaikinya.

Untuk mencari solusi dalam permasalahan yang ada maka peneliti membuat suatu sistem yang akan membantu dalam menyelesaikan masalah tersebut. Beberapa alternatif penyelesaian masalah diantaranya:

1. Merancang sistem informasi terkomputerisasi yang dapat membantu dalam data pegawai, absensi, penilaian kinerja pegawai dan cuti pegawai.

2. Perancangan database untuk sistem sehingga penyimpanan data tidak menggunakan media kertas lagi.

3. Data yang ada disimpan ke hardisk dan membuat backup-an data.

4. Membuat sistem informasi yang mudah dipahami oleh bagian admin agar mudah digunakan oleh setiap pegawai yang ada pada Kantor Sektor 8 Dinas Penanggulangan Kebakaran dan Penyelamatan Jakarta Selatan

Diagram alir data merupakan suatu desain sistem secara logical yang berorientasi pada aliran suatu data tanpa mempertimbangkan lingkungan fisik tempat data tersebut disimpan. (Setyawan \& Wandyatmono, 2009). Gambaran sistem yang diusulkan untuk aplikasi kepegawaian dapat dilihat melalui diagram alir data (DAD) berikut ini :

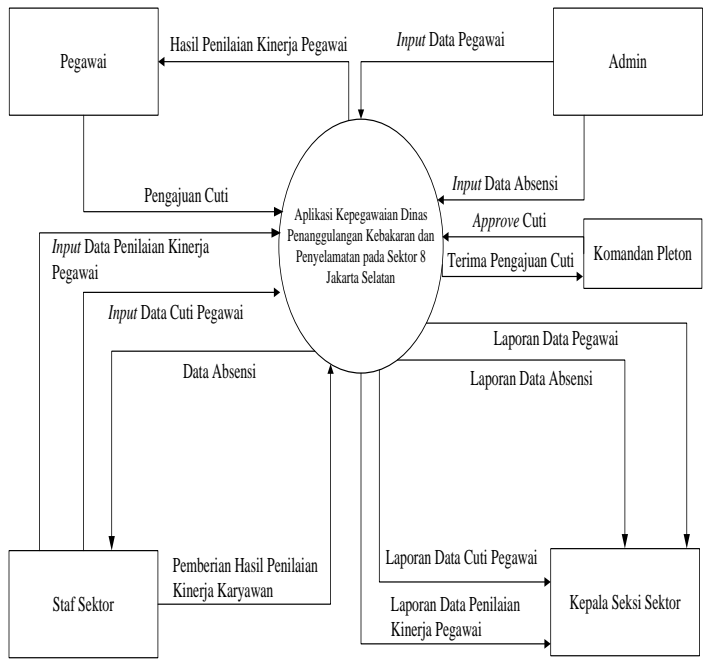

Gambar 1. Diagram Konteks Aplikasi Kepegawaian yang diusulkan 


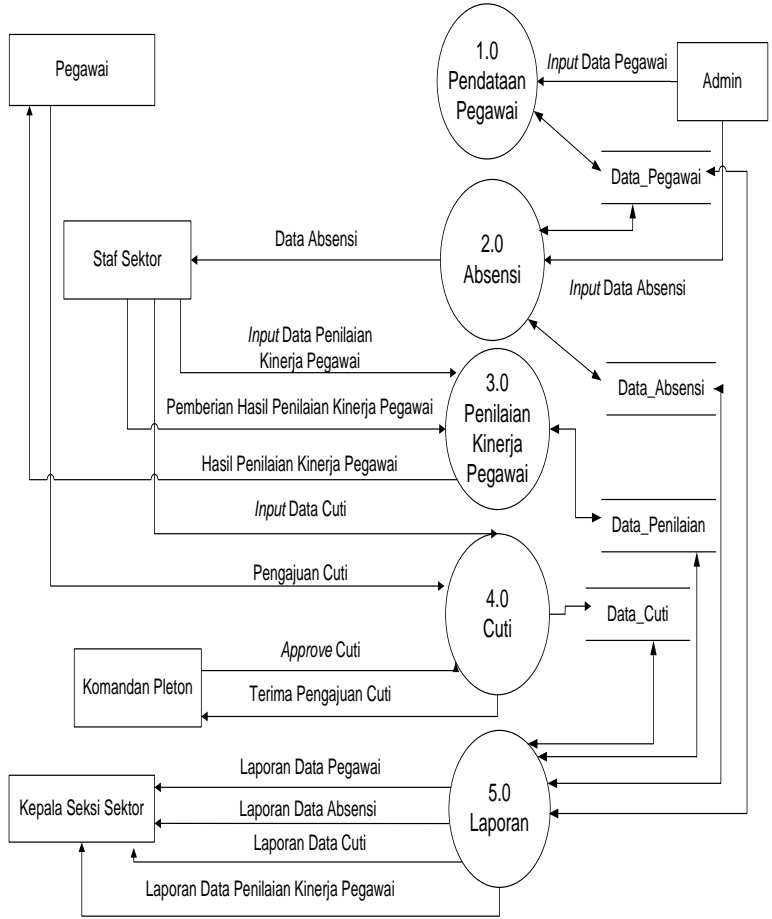

Gambar 2. Diagram Nol Aplikasi Kepegawaian yang diusulkan

Berdasarkan diagram alir data diatas, dapat dilihat bahwa sistem kepegawaian ini dimulai dari penginputan data pegawai oleh Admin perusahaan. Dan staff sektor dapat memproses pendataan data absensi pegawai, hasil penilaian kinerja pegawai dan data cuti pegawai, lalu pengajuan cuti yang diajukan oleh pegawai nantinya akan diterima pengajuannya oleh komandan pleton dan cuti pegawai dapat disetujui. Dari proses yang sudah dijelaskan bahwa Kepala Seksi Sektor nantinya akan mendapatkan laporan data pegawai, laporan data absensi, laporan data cuti dan laporan data penilaian kinerja pegawai sebagai bukti pelaporan setiap bulannya.

Entity Relationship Diagram (ERD) adalah gambaran data yang dalam sebuah diagram yang digunakan untuk dokumnetasi data dengan melihat hubungan antara entitas yang satu dengan entitas yang lainnya. (Larassati et al., 2019). Berikut ini adalah gambaran entity relationship diagram (ERD) untuk aplikasi kepegawaian :

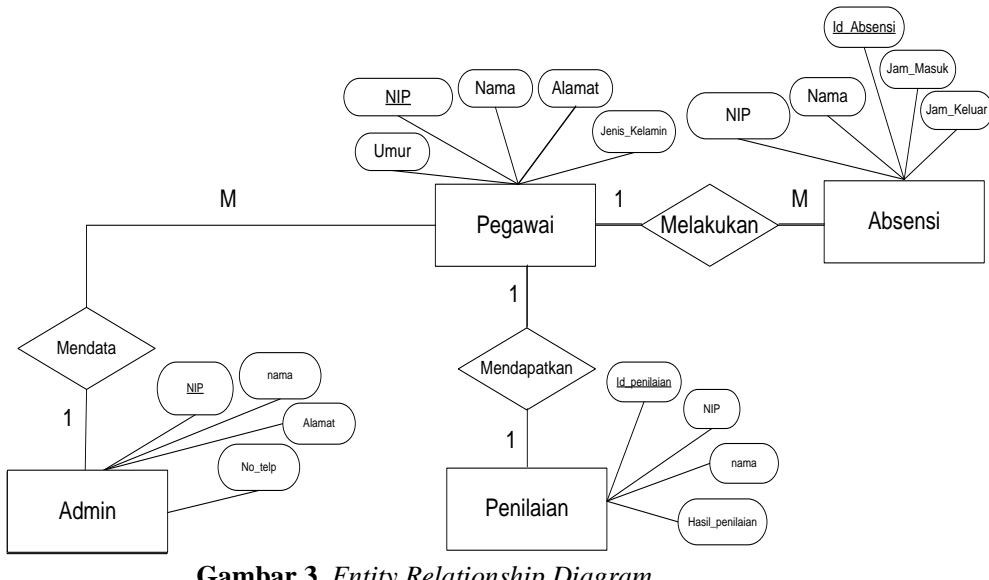

Normalisasi merupakan teknik untuk merancang tabel basis data relasional guna meminimalisir duplikasi data sehingga dapat menjaga basis data dari permasalahan unomaly update. (Pahlevi, 2013). 


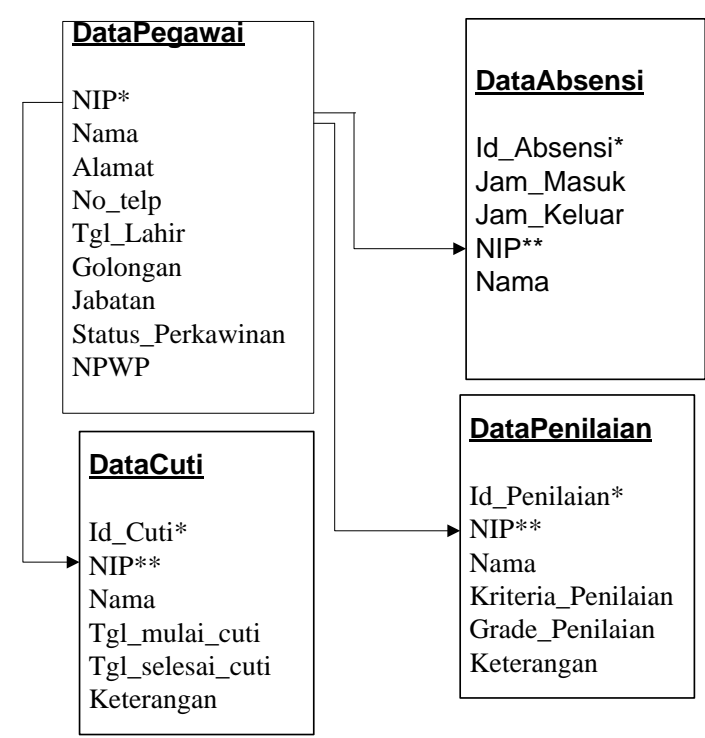

Gambar 4. Normalisasi pada Aplikasi Kepegawaian

Tampilan Layar Sistem Tampilan Layar Menu Utama

Master Pegawai Operasional Admin

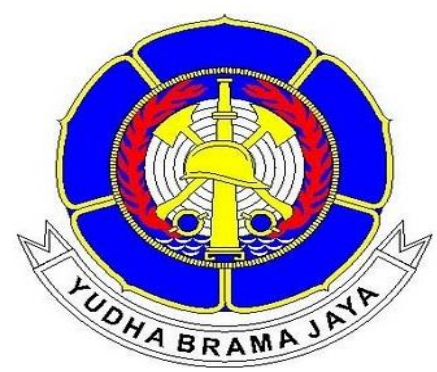

@2019 SEKTOR 8 DINAS PENANGGULANGAN KEBAKARAN DAN PENYELAMATAN JAKARTA SELATAN

Gambar 5. Tampilan Layar Menu Utama

Tampilan menu utama merupakan tampilan awal saat program aplikasi dijalankan. Tampilan utama berisikan menu-menu yang dapat digunakan untuk mengolah data pada sistem informasi kepegawaian Kantor Sektor 8 Dinas Penanggulangan Kebakaran dan Penyelamatan Jakarta Selatan. 


\section{Tampilan Layar Data Pegawai}

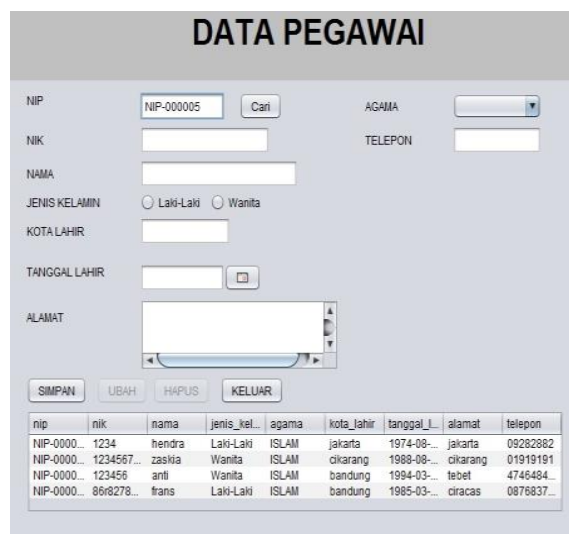

Gambar 6. Tampilan Layar Data Pegawai

Tampilan form masukan biodata berfungsi untuk memasukan atau menambah informasi data pegawai ke basis data,merubah data dan identitas lain dan menghapus data pegawai.

\section{Tampilan Layar Data Absensi Pegawai}

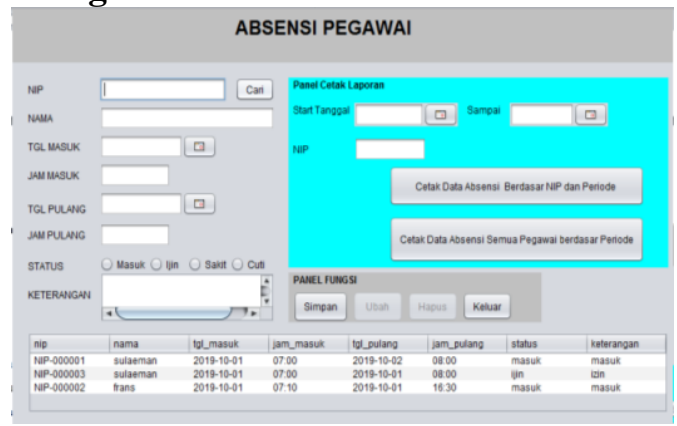

Gambar 7. Tampilan Layar Data Absensi Pegawai

Tampilan form masukan absensi berfungsi untuk memasukan atau menambah data riwayat absensi pegawai sebagai back up absensi pegawai ke basis data, merubah data riwayat absensi pegawai, dan menghapus data riwayat absensi pegawai. Hasil data riwayat absensi pegawai dapat langsung dilihat pada tabel laporan dibawah form masukan absensi pegawai

\section{Tampilan Layar Data Kinerja Pegawai}

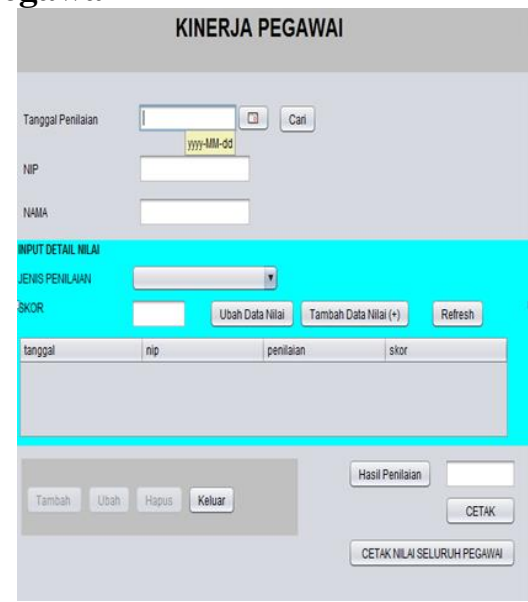

Gambar 8. Tampilan Layar Data Kinerja Pegawai

683 
Tampilan form masukan kinerja berfungsi sebagai penilaian kinerja pegawai dan memasukan atau menambah data penilaian kinerja pegawai ke basis data, merubah data penilaian kinerja pegawai, dan menghapus data penilaian kinerja pegawai.

\section{Tampilan Layar Laporan Data Pegawai}

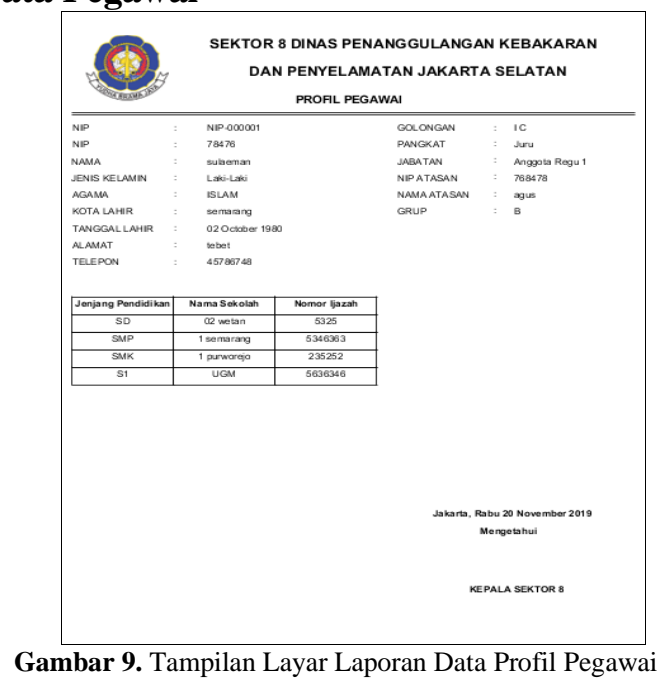

Tampilan keluaran laporan profil pegawai berisikan informasi lengkap data pegawai meliputi golongan, pangkat, biodata, riwayat pendidikan. Informasi data pegawai ini sesuai dengan basis data yang di input oleh Admin. Laporan ini dapat dicetak dan menjadi laporan informasi data pegawai secara lengkap.

\section{Tampilan Layar Laporan Absensi Pegawai}

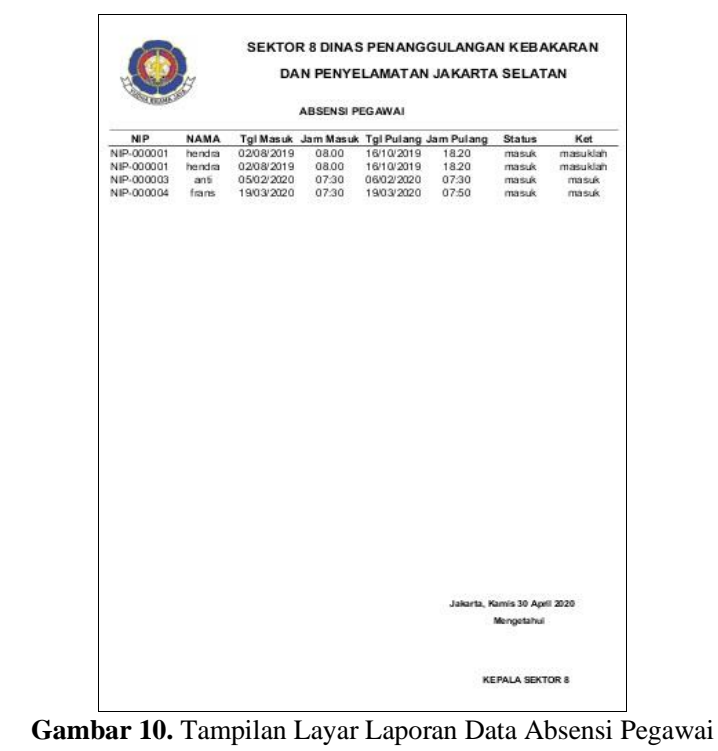

Tampilan keluaran laporan absensi seluruh pegawai berisikan informasi riwayat absensi pegawai.Laporan absensi pegawai sesuai dengan basis data yang di input oleh admin,data absensi dapat di cetak dan menjadi laporan informasi riwayat absensi pegawai secara lengkap. 


\section{Tampilan Layar Laporan Kinerja Pegawai}

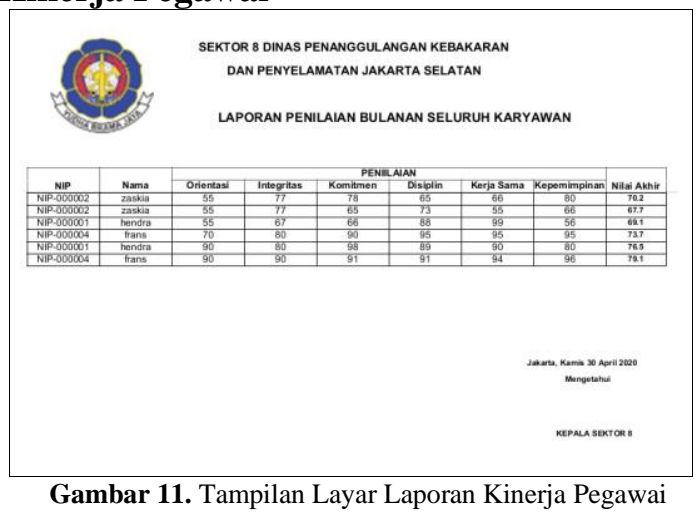

Tampilan keluaran laporan kinerja seluruh pegawai berisikan informasi penilaian pegawai yang meliputi orientasi, integritas, komitmen, disiplin, kerjasama dan kepemimpinan dalam waktu bekerja di lingkungan Kantor Sektor 8 Dinas Penanggulangan Kebakaran dan Penyelamatan Jakarta Selatan, maupun pada saat menjalakan tugas kerja diluar. Laporan kinerja pegawai sesuai dengan basis data yang di input oleh admin. Laporan kinerja pegawai ini dapat dicetak dan menjadi laporan informasi penilaian kinerja seluruh pegawai secara lengkap.

\section{SIMPULAN}

Perancangan sistem informasi kepegawaian ini dimaksudkan untuk meningkatkan kinerja pada Kantor Sektor 8 Dinas Penanggulangan Kebakaran dan Penyelamatan Jakarta Selatan, dalam melakukan pengolahan data menjadi tersimpan rapi, terkendali, sederhana, dan tidak membutuhkan waktu lama serta administrasi menjadi lebih teratur. Dan dengan diterapkannya sistem informasi kepegawaian secara terkomputerisasi, diharapkan staff sektor mampu dengan cepat dalam mengambil langkah dan keputusan, karena sistem informasi kepegawaian ini bersifat otomatis dan sudah disesuaikan dengan kebutuhan pada Kantor Sektor 8 Dinas Penanggulangan Kebakaran dan Penyelamatan Jakarta Selatan, sehingga mengefisiensikan waktu kerja.

\section{DAFTAR PUSTAKA}

Abdurahman, H., \& Riswaya, A. R. (2014). Aplikasi Pinjaman Pembayaran Secara Kredit Pada Bank Yudha BHakti. Aplikasi Pinjaman Pembayaran Secara Kredit Pada Bank Yudha BHakti, 8(2), 61-69. http://jurnal.stmikmi.ac.id/index.php/jcb/article/view/114/138

Fachlevi, M. R., \& Syafariani, R. F. (2017). Perancangan Sistem Informasi Kepegawaian Berbasis Website Di Bagian Kepagawaian Sdn Binakarya I Kabupaten Garut. Simetris : Jurnal Teknik Mesin, Elektro Dan Ilmu Komputer, 8(2), 553. https://doi.org/10.24176/simet.v8i2.1436

Larassati, M., Latukolan, A., Arwan, A., \& Ananta, M. T. (2019). Pengembangan Sistem Pemetaan Otomatis Entity Relationship Diagram Ke Dalam Database. Jurnal Pengembangan Teknologi Informasi Dan Ilmu Komputer, 3(4), 4058-4065. http://j-ptiik.ub.ac.id/index.php/j-ptiik/article/view/5117

Mardiasmo. (2011). Perpajakan Edisi Revisi. Andi Offset.

Pahlevi, D. S. M. (2013). Tujuh Langkah Praktis Pembangunan Basis Data. Elex Media Komputindo.

Prasetyo, I. (2014). Teknik Analisis Data Dalam Research and Development. UNY: Fakultas Ilmu Pendidikan, 6, 11. http://staffnew.uny.ac.id/upload/132310875/pengabdian/teknik-analisis-data-dalam-research-and-development.pdf

Prasojo, M. (2011). Pengantar Sistem Informasi Manajemen. CV. Remadja Karya.

Priyanti, D. (2013). Sistem Informasi Data Penduduk Pada Desa Bogoharjo Kecamatan Ngadirojo Kabupaten Pacitan. IJNS Indonesian Journal on Networking and Security, 2(4), 56. ijns.org

Putra, N. (2011). Research and Development, Penelitian dan Pengembangan: Suatu Pengantar. PT Raja Grafindo Persada. Rumetna, M. S., Lina, T. N., \& Santoso, A. B. (2020). Rancang Bangun Aplikasi Koperasi Simpan Pinjam Menggunakan Metode Research and Development. Simetris: Jurnal Teknik Mesin, Elektro Dan Ilmu Komputer, 11(1), 119-128. https://doi.org/10.24176/simet.v11i1.3731

Setyawan, A., \& Wandyatmono, J. (2009). Sistem Informasi Penggajian Pegawai Kecamatan Geneng Kabupaten Ngawi. Jurnal Speed - Sentra Penelitian Engineering Dan Edukasi, 1(3), 44-50. 